\title{
Challenges of Transferring Burn Victims to Hospitals: Experiences of Emergency Medical Services Personnel
}

\author{
Hamid Reza Khankeh ${ }^{1,2}$, Razieh Froutan ${ }^{3}$, Masoud Fallahi-Khoshknab ${ }^{1}$, Fazlollah Ahmadi ${ }^{4} \&$ Kian Norouzi ${ }^{1}$ \\ ${ }^{1}$ University of Social Welfare \& Rehabilitation Sciences, Tehran, Iran \\ ${ }^{2}$ Department of Clinical Science and Education, Karolinska Institutet, Stockholm, Sweden \\ ${ }^{3}$ School of Nursing and Midwifery, Mashhad University of Medical Science, Mashhad, Iran \\ ${ }^{4}$ Department of Nursing, Faculty of Medical Sciences, Tarbiat Modares University, Tehran, Iran \\ Correspondence: Razieh Froutan, School of Nursing and Midwifery, Mashhad University of Medical Science, \\ Mashhad, Iran. Tel: 98-91-51-191-124. E-mail: froutanr@mums.ac.ir
}

\author{
Received: February 3, 2016 Accepted: March 10, 2016 Online Published: March 23, 2016 \\ doi:10.5539/gjhs.v8n11p206 URL: http://dx.doi.org/10.5539/gjhs.v8n11p206
}

\begin{abstract}
A thorough understanding of experiences of Emergency Medical Services (EMS) personnel related to the field transfer of burn victims can be used as a prerequisite of quality improvement of pre-hospital clinical care for these kinds of victims. The aim of the present study was to explore the experiences of EMS personnel during transferring burn victims. In this qualitative research, content analysis was performed to explore the experiences and perceptions of a purposeful sample of Iranian EMS personnel $(n=32)$. Data collection continued until a point of saturation was reached. Data was collected using in-depth semi-structured interview and field observations and analyzed by qualitative inductive content analysis.
\end{abstract}

After data analyzing from experiences of pre-hospital emergency personnel during transferring burn victims 7 subcategories were developed and classified into three main categories as challenges of transferring burn victim including; risks during patient transfer, restrictions in the admission of burn victims and uncertainties about patient referral. This study showed that different factors affect the quality of pre-hospital clinical services to the field transfer of burn victims that should be considered to improve the quality of pre-hospital clinical care of burn victims in dynamic programs. Further investigation is needed to explore the process of these crucial services.

Keywords: burn victims, emergency medical services (EMS) personnel, content analysis, qualitative study

\section{Introduction}

As statistics have indicated, burn injuries occur in one individual per 17 seconds, worldwide. Approximately six million people are estimated to suffer from burn injuries each year. Overall, burn injury is one of the major causes of morbidity and mortality, accounting for 5-12\% of all traumas (Aghakhani et al., 2015; Olaitan \& Olaitan, 2005).

According to a report by World Health Organization (WHO) more than 300,000 people die annually due to burn complications around the world (Mock et al., 2011). The number of burn injuries is reported to be 150,000 cases in Iran annually (population of 75 million), while this rate is estimated at 500,000 cases in the United States (population of 320 million). The comparison between these two countries is indicative of the higher rate of burn injuries in Iran, compared to the United States. In total, 2000 people die annually as a result of burns (Azizi et al., 2014).

Burns are regarded as pre-hospital emergency situations, given the associated fatal complications. Considering the fact that severe injuries caused by burns can lead to irreversible damages and even death in some cases, proper and urgent care is required to avoid further damages during patient transfer. Based on a study by Van der Velden, pre-hospital period is the golden time for patient revival (van der Velden et al., 2008).

Additionally, Skinner et al. showed that the main responsibility of pre-hospital emergency personnel before patient transfer is to rescue the injured victims within a shorter time than the standard (Skinner, 2008). In fact; timely transfer of patients to hospitals is one of the most important principles of pre-hospital emergency care. 
Therefore, utilization of standard and well-equipped ambulances is necessary for providing proper emergency care and saving the lives of victims during hospital transfer.

Also, in a study by Lungu et al., the importance of timely transfer of victims from the accident scene to the hospital was highlighted as a key factor in pre-hospital emergency care (Lungu, Kamfose, Chilwa, \& Hussein, 2000). As Joshipura et al. indicated, attending burn victims during hospital transfer is a basic principle of pre-hospital care. In fact, absence of or defects in patient transfer systems are identified as the main barriers to patients' access to pre-hospital care services (Joshipura, Shah, Patel, Divatia, \& Desai, 2003). Moreover, Chen et al. showed that the highest level of nurses' stress is related to patient safety (Chen, Lin, Wang, \& Hou, 2009).

Today, significant attention is being paid to the use of standard ambulances for timely transfer of burn victims to healthcare centers, since in emergency situations, equipped ambulances play the most important role in saving patients' lives and reducing mortality (Health Ministry of Iran, 2007).

Considering the adverse consequences related to deficiencies in emergency care, Jaslow et al. showed that mortality and morbidity rates due to lack of proper emergency care were quite high in low- and middle-income countries (Jaslow, Ufberg, \& Marsh, 2003). In this regard, in a study by Siddiqui, the most common preventable errors included delays in primary care and failure in adequate patient care during patient transfer (Siddiqui, Zafar, $\&$ Bashir, 2004).

In Iran, there is limited information about the transport of burn victims to hospitals and the associated factors in real-life environments; therefore, understanding this process and the involved factors is of pivotal importance. Here, multiple unanswered questions arise regarding the process of patient transfer: How does this process take place in actual environments? What are the factors affecting the transfer of burn victims in pre-hospital emergency situations? How do emergency medical personnel transfer burn victims under stressful circumstances and limited amount of time, while facing unexpected and unpredictable events?

Since challenges of transferring burn victims to hospitals have not been well studied, the current research attempted to explore emergency medical services (EMS) personnel's experiences of transferring burn patients to hospitals in Tehran, Iran

\section{Method}

\subsection{Study Design}

In the present study, a qualitative approach using inductive content analysis was applied, since it could help us to understand emergency medical services (EMS) personnel's experiences of transferring burn patients to hospitals deeply, though comprehensive description of participants' experiences. The analysis abstracted the experiences of EMS personnel in a number of concepts and categories.

With no prior hypothesis, data were collected by focusing on interviewees' points of view. Different codes and categories were extracted, using an inductive approach. Subsequently, the derived codes were conceptually classified, considering their properties and dimensions (Speziale, Streubert, \& Carpenter, 2011; Strauss \& Corbin, 1998).

\subsection{Study Setting and Population}

Pre-hospital EMS staffs were interviewed in Tehran, the capital and largest city of Iran with 13 million population (Statistical Centre of Iran, 2014). Several call centers provide the required number of EMS vehicles throughout the city. The present study enrolled a purposive sample of 32 EMS-related experts and authorities, including 20 emergency technicians, five emergency care support workers, three anesthesiologist assistants, and four nurses (Table 1). The inclusion criterion was a prior experience of providing care for burn victims. For ensuring diversity, participants were selected from various age groups with different educational levels, working experiences and organizational roles. 
Table 1. Participant characteristics

\begin{tabular}{llll}
\hline No & Age & Position & Work history (Year) \\
\hline 1 & 28 & Emergency Technician & 7 \\
2 & 29 & Anesthesia Technician & 9 \\
3 & 32 & Emergency Technician & 10 \\
4 & 42 & Emergency Technician & 16 \\
5 & 33 & Rescue & 9 \\
6 & 33 & Nurse & 9 \\
7 & 35 & Emergency Technician & 12 \\
8 & 26 & Emergency Technician & 6 \\
9 & 37 & Emergency Technician & 13 \\
10 & 35 & Emergency Technician & 11 \\
11 & 38 & Emergency Technician & 15 \\
12 & 26 & Nurse & 5 \\
13 & 43 & Emergency Technician & 16 \\
14 & 36 & Emergency Technician & 14 \\
15 & 38 & Emergency Technician & 15 \\
16 & 38 & Emergency Technician & 14 \\
17 & 33 & Nurse & 10 \\
18 & 35 & Nurse & 12 \\
19 & 28 & Emergency Technician & 8 \\
20 & 32 & Emergency Technician & 9 \\
21 & 26 & Emergency Technician & 7 \\
22 & 37 & Emergency Technician & 12 \\
23 & 37 & Emergency Technician & 15 \\
24 & 31 & Anesthesia Technician & 10 \\
25 & 30 & Emergency Technician & 9 \\
26 & 35 & Emergency Technician & 12 \\
27 & 32 & Anesthesia Technician & 11 \\
28 & 39 & Emergency Technician & 17 \\
29 & 34 & Rescue & 12 \\
30 & 35 & Rescue & 12 \\
31 & 32 & Rescue & 13 \\
32 & 38 & Rescue & 16 \\
\hline & & & \\
\hline
\end{tabular}

\subsection{Data Collection}

Data were collected using in-depth semi-structured interviews and field observation. The interview guide included general and specific questions to direct the interview. Some examples are as follows:

1)- Would you please let me know about your experiences on the transfer of burn victims to hospital?

2)-What problems have you faced during the transfer of burn victims?

3)-How did you provide emergency care services during the transfer of burn victims to hospital?"

The participants were asked to elaborate on their answers when necessary. Generally, each interview lasted between 40-60 minutes by one single interviewer in Farsi language. The audiotaped interviews were transcribed 
verbatim. All interviews were performed by the first author and digitally recorded after obtaining the consent of EMS staff. The interviewer was an expert in qualitative research (perfectly trained in qualitative courses and workshops), with 18 years of experience in emergency burn units.

\subsection{Data Analysis}

A content analysis approach was adopted to analyze the data. First, the recorded interviews were transcribed verbatim and the transcripts were reread several times to obtain an overall understanding of their content (familiarization).

Then, various codes were extracted and compared based on their differences and similarities and based on common properties or dimensions, similar codes were classified in higher-level categories with a new and high abstract label. Researchers performed data collection/analysis simultaneous and selection of study samples continued until data saturation.

\subsection{Trustworthiness}

The content analysis method recommended by Lundmen and Grancheim, which is comprised of five stages, was used to ensure the rigor of this study (Graneheim \& Lundman, 2004). Four criteria of creditability, transferability, dependability and conformability provided a framework to determine the validity and reliability of the results (Polit \& Beck, 2004). Prolonged engagement with the participants in the field from September 2013 to March 2015 helped the researchers gain the trust and support of the participants for data collection.

During data collection, the participants were asked to validate the results of analysis and confirm that they reflected their experiences (member checking). In an effort to ensure the credibility of the research and facilitate the unbiased judgement of the findings by the readers, the authors attempted to present the participants' statements with fidelity. External audit was used to establish both dependability and confirmability. Therefore, experts not involved in the research process, were provided with the interviews and the extracted codes, sub-categories and categories and asked to check if the results of the analysis were supported by the data. External check was performed by the first and second authors, who were both experts in pre-hospital emergency care. Peer checking was then carried out by two PhD students with an experience in pre-hospital care (Suserud, 2002). Furthermore; maximum sampling variation supported the transferability of data.

\subsection{Ethical Considerations}

This research project was approved by the Ethics Committee of the University of Social Welfare and Rehabilitation Sciences (code: 3113/2/A/ 801/91) in July 2012 by considering the above-mentioned guidelines.

\section{Results}

The age range of the participants was within $26-43$ years, with an average of $33.28 \pm 4.8$ years. The mean duration of working experience was $11.28 \pm 3.4$ years. All participants had more than five years of experience in working with patients with burn injuries and performing pre-hospital emergency care.

From the data analysis, 7 subcategories were developed. After several reviewing and summarizing and based on similarities and differences, finally three main contributing categories were formed through the content analysis method including: 1) risks during patient transfer, 2) restrictions in the admission of burn victims 3 ) uncertainties about patient referral (Table 2).

Table 2. Categories and sub-categories of challenges in transferring burn victims and some extracted codes

\begin{tabular}{|c|c|c|c|c|}
\hline Theme & & Categories & Sub-categories & Codes \\
\hline \multirow{3}{*}{$\begin{array}{l}\text { Challenges } \\
\text { Transfer }\end{array}$} & \multirow{3}{*}{ in } & \multirow{2}{*}{$\begin{array}{l}\text { Risks during patient } \\
\text { transfer }\end{array}$} & $\begin{array}{l}\text { Threats against patient } \\
\text { safety }\end{array}$ & $\begin{array}{l}\text { Restlessness and agitation of burn victims } \\
\text { Victim's loss of balance in a moving } \\
\text { ambulance }\end{array}$ \\
\hline & & & Jeopardizing patient's life & $\begin{array}{l}\text { Inadequate space for patient monitoring } \\
\text { Personnel's loss of balance in a moving } \\
\text { ambulance }\end{array}$ \\
\hline & & $\begin{array}{l}\text { Restrictions in the } \\
\text { admission of burn victims }\end{array}$ & Shortage of expert staff & $\begin{array}{l}\text { Lack of burn specialists } \\
\text { Personnel's lack of specialized skills for } \\
\text { the management of burn accidents }\end{array}$ \\
\hline
\end{tabular}




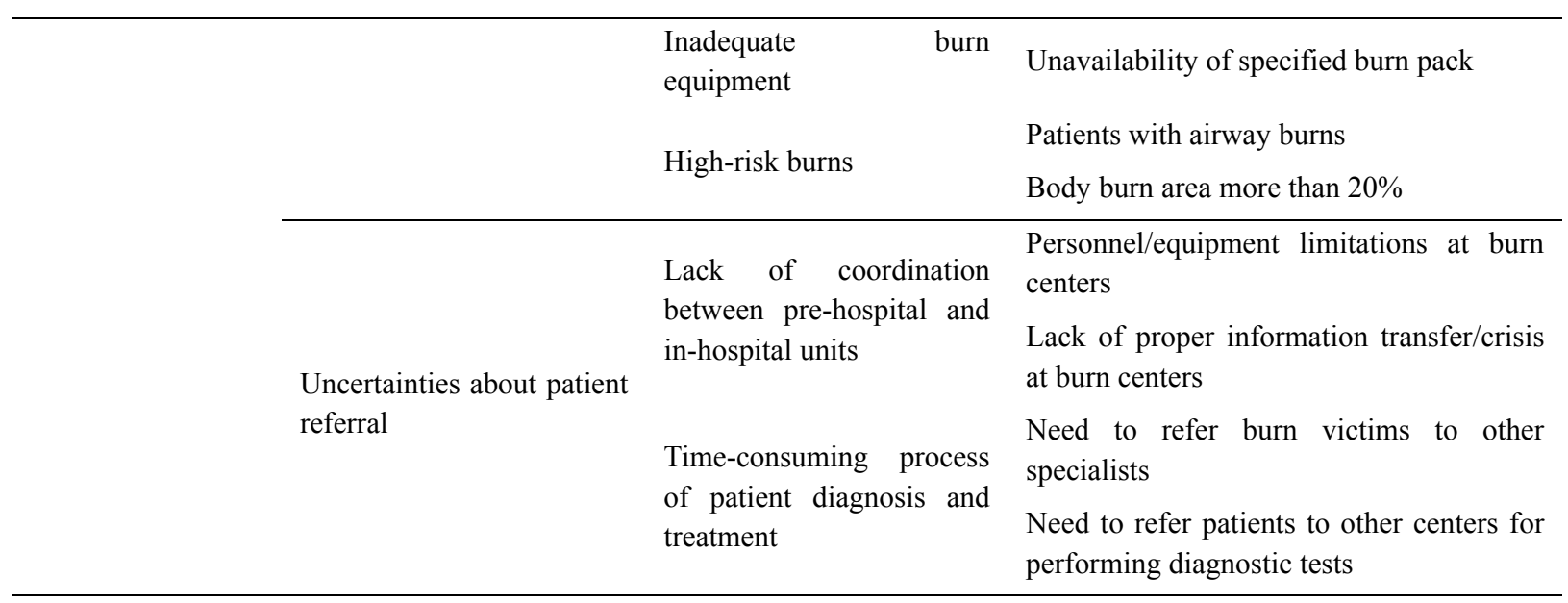

Burns and the associated injuries are exclusive events, with significant deleterious effects on individuals. The obtained results showed that the transfer of burn victims was a challenging experience for pre-hospital EMS personnel. In many cases, these providers faced difficulties in monitoring and implementing clinical measures during patient transfer to hospitals due to the unavailability of standard and equipped ambulances.

Therefore, many healthcare centers refused to admit patients with severe burns. Also, lack of coordination between the pre-hospital and in-hospital staff, limited number of personnel at specialized burn hospitals and inadequate equipments led to uncertainties in pre-hospital EMS personnel at the time of patient referral.

In this study, three major categories composed of several sub-categories, were extracted by the analysis of hand-written notes and interviews. These categories and sub-categories are described in the following sections.

\section{Risks during patient transfer}

In this study, "risks during patient transfer" was one of the challenges which has been extracted from experiences and perceptions of the study participants. This category consisted of two major sub-categories: "jeopardizing the victim's safety" and "jeopardizing the victim's life". These sub-categories are described below.

Jeopardizing the victim's safety

The EMS personnel and burn victims may lose their balance while the ambulance is on the move or passing over road bumps. Under such circumstances, considering the restlessness and agitation of burn victims, the intravenous catheter may be detached from the patient and the victim might fall off the stretcher.

The participants believed that the safety of burn victims may be jeopardized as a result of imbalance during patient transfer due to the non-standard condition of ambulances. In this regard, EMS personnel No. 11 said:

"...The ambulance kept bouncing during the ride...The patient's vessel burst out... I could not do anything for the victim under such circumstances..."

Also, loss of balance in EMS personnel was described by EMS personnel No. 5:

"... As I opened the rear door of the ambulance, I saw my colleague holding on to his seat with two hands since he had to maintain his balance to avoid falling off his seat..."

One of the emergency medical technicians referred to the complaints of patients' companions about non-standard ambulances:

"...Many of those who accompany burn victims have issued their complaints about ambulance rides. As they say, healthy people may get hurt during the ride, let alone the patients..."

Regarding the risk of patients' falling off the stretcher due to restlessness and agitation, EMS personnel No. 7 said:

"...The burn victim was sitting on the stretcher because of restlessness and agitation... The patient was regularly hit to the cabin and kept falling off the scoop stretcher."

Jeopardizing the patient's life:

"Jeopardizing the patient's life" was one of the derived challenges. Rapid transfer of burn victims to the hospital is one of the main goals of pre-hospital EMS providers. However, heavy traffic of Tehran city prevents this 
process, leading to delays in the implementation of advanced therapeutic measures for burn victims. Inappropriate ambulance cabins for patient monitoring and delays in providing advanced therapeutic measures were included in this sub-category. The participants believed that ambulance cabins are not suitable for patient monitoring and providing clinical services. In this regard, participant No. 12 said:

"... The breathing status of the patient needed to be regularly monitored until hospital admission...The patient had trouble breathing ... But I could not do anything inside the cabin on the move."

With regard to delays in providing advanced therapeutic measures, the participants believed that standard equipments and specialized human resources are essential for patients with inhalation burns. However, delays in providing advanced clinical services threaten the patient's life. In this regard, EMS personnel No. 15 said:

"...A patient with a $60 \%$ burn was feeling agitated...I used the oxygen mask for the patient... The serum was connected and several pedestrians dispersed the coming cars to different directions... Finally, the victim was transferred to the hospital. Unfortunately, later, I informed that the patient had passed away!"

\section{Restrictions in the admission of burn victims}

According to the study results, "restrictions in the admission of burn victims" was the second inferred challenges. Many hospitals refused to accept victims with severe burns due to the shortage of trained personnel for dealing with these injuries and inadequate skills of the staff for bandaging the wound site. This category comprised of the following sub-categories: "shortage of specialized personnel and equipments" and "high-risk burns".

Shortage of specialized personnel and equipments:

The participants believed that burn injuries are exclusive events. Nurses and physicians believed that patients with severe burns should be immediately transferred to a specialized hospital, considering the need for skilled and experienced specialists. In this regard, EMS personnel No. 13 said:

"...The emergency physician refused to meddle in the treatment process as soon as he encountered the victim...As the doctor said, they did not accept such responsibilities under no circumstances...They neither had the burn specialists nor the skilled personnel..."

Another reason for admission rejection is explained by EMS personnel No. 18 as below:

“.. Hospital emergency personnel unit say they still do not possess facilities, complete and specified burn pack...”

High-risk burns:

"High-risk burns" was another derived sub-category. Many authorities and EMS personnel refused to accept patients with high-risk burns. The participants believed that patients with high-risk burns should be transferred to a specialized burn center after performing initial measures (e.g., venipuncture, serum therapy, insertion of a nasogastric tube and bladder catheterization) by the EMS personnel. In this regard, EMS personnel No. 19 indicated:

"...A 5-year-old child with burn injuries on the face was transferred to .... Hospital...But they refused to admit the patient... They said they were unable to admit patients with airway burns, as they had warned the dispatch center!"

Burn body surface area is another concern to hospital patient admission. Admission is not accepted if burn surface is more than $20 \%$. EMS personnel No. 8 stated:

"A patient with a $40 \%$ burn was transferred to the hospital. Unfortunately they refused to admit the patient. Because the burn body area was more $20 \%$..."

\section{Uncertainties about patient referral}

"Uncertainties about patient referral" was another category in this study. Usually, burn patients were transferred to burn centers without any prior coordination. "Lack of coordination between pre-hospital and in-hospital staff" and "time-consuming process of diagnosis and treatment of burn victims" were some bad consequences of this problem which can be interpreted from this important concept.

Lack of coordination between pre-hospital and in-hospital staff:

According to the participants' experiences, considering the shortage of hospital personnel and equipments during each shift specially in emergency department, hospital authorities should be immediately informed in case the number of burn victims transferred by EMS personnel will be increased. Therefore, the on-call personnel can attend the patients on time and prevent chaos at the hospital. In this regard, EMS personnel No. 17 said: 
“...The number of referred patients during night shifts was high, while only two staffs were present in the emergency department... We had not been informed about the accident... Motahari Burn Center faced a critical situation!"

\section{Time-consuming process of patient diagnosis and treatment:}

Considering the systemic complications, traumas and injuries of burn victims, the presence of specialists at hospitals is essential for the treatment process. However, there are various restrictions in admitting burn victims with traumas due to the absence of ophthalmologists, neurologists and other specialists and shortage of equipments and diagnostic facilities such as CT scan and MRI.

As the hospital staff stated, burn victims should go through a long process for physician consult and diagnostic tests (e.g., making appointments for physician consult, performing tests, transport and return to the center) and pay these costs. These processes lead to delays in the treatment of burn victims and prevent the provision of essential clinical services. In this regard, EMS personnel No. 16 said:

"...A burn victim with traumas was transferred to the burn center... The patient required consultation with a neurologist... After making repeated calls for making appointments with the specialist and performing CT scan, we realized that the patient's companion was out of money."

All three Key Concepts and subcategories are available at Figure 1.

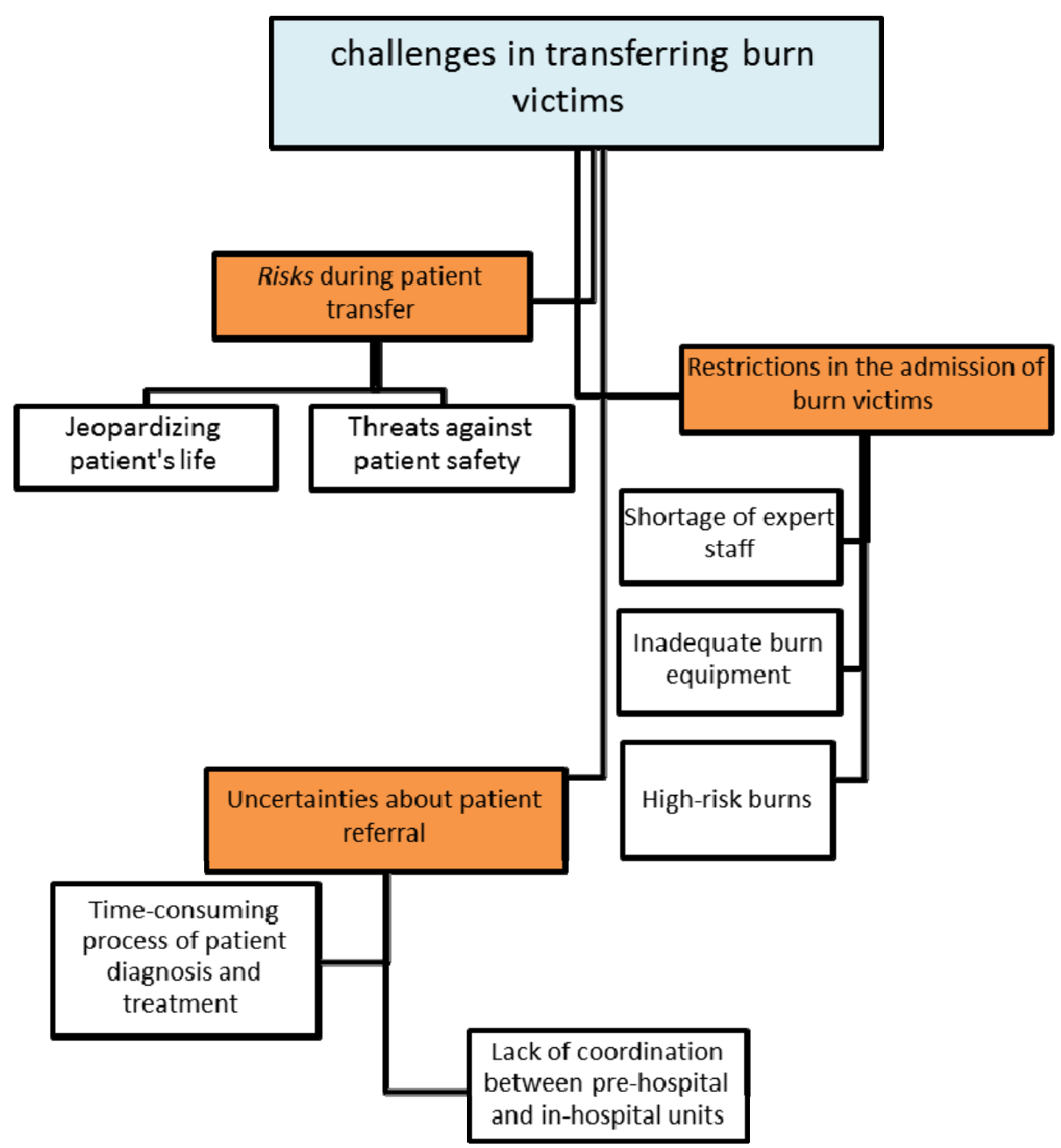

Figure 1. Three Key Concepts of challenges in transferring burn victims

\section{Discussion}

In this study, three main concepts as main challenges to transfer burn victims were extracted by analyzing the 
experiences and perceptions of pre-hospital EMS personnel. These challenges included "risks during patient transfer", "restrictions in the admission of burn victims", and "uncertainties about patient admission". These categories, based on their distinct properties, were composed of different related factors.

This research was one of the first qualitative studies to evaluate the experiences and perceptions of pre-hospital EMS personnel about the challenges to transfer of burn victims to burn centers in Iran.

Timely transfer of victims is one of the most important components of pre-hospital emergency care. Additionally, providing appropriate services during patient transfer requires standard and equipped ambulances in order to save the lives of patients who need urgent care. The results of our study showed that non-standard ambulances can jeopardize patients' safety, which in fact intensifies the stress and anxiety of EMS personnel. These findings were acquired from depth exploration are in the same line with the findings of our previous study (Froutan, Khankeh, Fallahi, Ahmadi, \& Norouzi, 2014). In this regard; Chen et al. showed that the highest stress level of nurses was related to patients' safety (Chen, Lin, Wang, \& Hou, 2009).

A specific set of diagnostic and therapeutic measures should be taken before patient transfer to hospitals. These measures play a significant role in reducing mortality and morbidity in patients and alleviating the negative consequences. However, inadequate emergency equipments and imbalance in the cabins of non-standard ambulances interfere with healthcare provision by pre-hospital EMS personnel. In many cases, they face difficulties in providing clinical services for burn victims. Consequently, they are troubled or unable to perform basic measures such as venous catheterization, monitoring and controlling the patient's airway and other clinical measures.

In this regard, Brice et al. in a study, entitled "Special Section: Safety in EMS", noted that out-of-hospital setting is unique to health care and presents many challenges to providing safe, high-quality medical care in emergency situations (Brice \& Daniel Patterson, 2012). According to a study by Bahadori et al., non-standard and poor patient transfer, which results from the use of non-standard ambulances, bumpy roads and traffic congestion, is one of the major challenges of pre-hospital EMS personnel (Bahadori, Ravangard, \& Nejati, 2012). However, it seems that patient transfer is highly noted in developed countries. As Fuller et al. indicated, some countries such as Canada have comprehensive programs to provide emergency services during the transfer of patients, such as children with burn injuries (Fuller \& Herold, 2002).

The present findings showed the inadequacy of medical equipments and standard ambulances for transferring burn victims to specialized hospitals; this issue negatively affected the efficiency and effectiveness of human resources. Therefore, planning and financial investment for quality improvement of pre-hospital emergency care are necessary in order to equip and standardize ambulances.

In this regard, Imaniyeh et al. highlighted the importance of advanced medical equipments in healthcare system and patient follow-up, diagnosis and treatment (Imaniyeh \& Rahmdar, 2004). As previously mentioned access to standard ambulances and advanced medical equipments in pre-hospital emergency settings is of pivotal importance due to time limitations in providing medical services for the injured victims who are in serious life threatening situation..

"Restrictions in the admission of burn victims" was another category, explored from EMS personnel experiences about the referral of burns victims to burn centers. According to the obtained results, many hospitals and burn centers refused to accept patients with burn injuries greater than $20 \%$ and those with airway burns due to inadequate skills of healthcare providers and insufficient equipments in emergency department for the treatment of burn victims. Therefore, despite the heavy traffic of Tehran, the staff of 115 dispatch center had no choice but to transfer the patients to specialized hospitals, considering the emergency and life-threatening conditions of the victims.

The preparedness of EMS personnel is essential for treatment success and plays an important role in providing high-quality services for burn victims. Hospitals are the main centers for the admission of patients with accident injuries (e.g., burns) and are involved in the consequences of such incidents. Therefore, a coherent program should be designed to deal with such events.

On the other hand, hospitals are complex and potentially vulnerable institutions. Lack of effective human resources and essential equipments leads to reduced access to healthcare services and care for patients and victims. Therefore, hospitals, especially emergency departments, should be always prepared for handling such events (Asgari, 2007; World Health Organization, 2007a).

In fact, improving the performance of hospitals for prompt and accurate management of burn accidents is one of the most important strategies for reducing burn complications; this can lead to reduced mortality rates from 
burns (Haidary \& Arabshahi, 2006). It seems that healthcare systems are not well prepared for effective crisis management (Ghanbari et al., 2011; Khankeh, 2007). One of the major problems of hospitals in our country regarding crisis management is the inability to prepare hospitals accordingly.

Hospitals, as the most important part of healthcare systems, play a vital role in the management of natural and human disasters. Level of preparedness at hospitals can be improved in case the staff can perform their tasks efficiently and coordinatively under emergency circumstances (Imaniyeh \& Rahmdar, 2004; Vahedparast, 2005; World Health Organization, 2007a). In fact, preparedness for unforeseen disasters, especially at hospitals, is the priority of disaster management programs at both national and international levels, especially in disaster-prone countries (Falvo, 2004).

One of the strategies for reducing systemic side-effects and improving the preparedness of hospitals is to promote prompt and proper reactions to burn accidents (Bergin \& Khosa, 2007). Regarding this important issue, executive decisions must be made quickly and accurately, given the unpreparedness of medical centers and hospitals in our country and the unexpected nature of the majority of natural and human disasters such as burns. Hospital staff, especially nurses, who play a key role in crisis management, must be able to provide the required care in the shortest time possible; also, they should be able to direct human resources in times of crisis (Raies Akbari, Yavari, \& Hadi, 2005).

Moreover, the results of this study showed that burn victims undergo a lengthy and costly process for transfer to hospitals, consults with specialists and undergoing diagnostic tests, given the shortage of specialists (e.g., ophthalmologists, neurologists and other specialists), lack of equipments and facilities such as CT and MRI units and triage of burn victims by emergency technicians. This long process leads to delays in treatment and clinical measures for burn patients.

"Uncertainties about patient referral" was the last challenge understood from the experiences of EMS personnel about the referral of burn victims to specialized burn centers. The results of the present study indicated a lack of coordination between EMS personnel and in-hospital staff regarding the transfer of burn patients.

Coordination is known as the main factor for providing pre-hospital care in burn injuries. In fact, WHO introduces coordination as the main principle of health care provision during emergencies and disasters. Moreover, new solutions and strategies have been introduced to promote synchronization between EMS personnel and in-hospital staff (Vahedparast, 2005; van der Velden et al., 2008). Additionally, Manitoba Organization has highlighted the importance of coordination between various healthcare centers and institutions. In fact, the success of emergency management programs depends on the coordination between the involved organizations and their activities before, during and after emergencies (Raies Akbari, Yavari, \& Hadi, 2005).

In our study, data analysis revealed a lack of coordination between Emergency Dispatch Center 115 and EMS personnel for patient admission to hospital, leading to delays in providing specialized care for burn victims. In total, lack of coordination was identified as the most important obstacle to the success of crisis management and provision of care services in natural and human disasters (Khankeh, 2007; Vahedparast, 2005; World Health Organization, 2007b)

As conclusion, Although the understanding and experiences of pre-hospital EMS personnel in this study about the referral and admission of burn patients cannot be generalized to all countries (restricted to a certain culture), the findings could have numerous applications in many areas. The present study showed that various factors affect the quality of patient referral. Some factors such as uncertainties about patient referral" were similar among all emergency cases, while other factors such as risks during patient transfer and restrictions in the admission of burn victims were serious threats to the quality of patient referral. Since severe injuries caused by burns can lead to irreversible damages and even death, proper and prompt care should be applied immediately during patient transfer. Therefore, pre-hospital emergency authorities should adopt systematic and dynamic policies to improve the referral of burn patients by using standard ambulances and advanced equipments.

\section{Strengths and Limitations}

This research was one of the first qualitative studies for determining the experiences of pre-hospital EMS personnel about the referral of burn patients to specialized burn centers in Tehran, Iran. This study could provide valuable information on the experiences of pre-hospital EMS personnel about the referral of burn patients to hospitals. Therefore, the limitations and strengths of this study should be considered, as well. Since semi-structured interviews were conducted for data collection, the gathered information was considered inclusive. 


\section{Acknowledgments}

The authors would like to express their gratitude to all the personnel who participated in this study.

\section{Conflict of Interest}

The authors declare that there is no conflict of interests regarding the publication of this paper.

\section{References}

Aghakhani, K., Abdolkarimi, L., Memarian, A., Hosseini, R., Mehrpisheh, S., Abdolkarimi, F., \& Heidari, M. (2015). Epidemiology of occupational burn injuries and its effect on patients referred to Motahari Hospital in Tehran during 2010 to 2012. Razi Journal of Medical Sciences, 21(128), 66-71.

Asgari, A. (2007). In the Search of Management and Planning principals. Paper presented at the International Congress of Crisis Management in Disasters Tehran University, Tehran.

Azizi, A., Zarei, J., Nabovati, E., Vakili-Arki, H., Abbasi, E., \& Razavi, A. (2014). Determining of the Factors Affecting Mortality in Burn Patients Using a Decision Tree Data Mining Algorithm. Journal of Health Administration, 16(54), 34-45.

Bahadori, M., Ravangard, R., \& Nejati, M. (2012). Development of Emergency Medical Services (EMS) in Iran: Component of Transportation. HealthMED, 826.

Bergin, A., \& Khosa, B. (2007). Are we ready? Healthcare preparedness for catastrophic terrorism (pp. 1-19). Australian Strategic Policy Institute.

Brice, J. H., \& Daniel Patterson, P. (2012). Special Section: Safety in EMS. Prehospital emergency care: official journal of the National Association of EMS Physicians and the National Association of State EMS Directors, 16(1), 1. http://dx.doi.org/10.3109/10903127.2011.627108

Chen, C.-K., Lin, C., Wang, S.-H., \& Hou, T.-H. (2009). A study of job stress, stress coping strategies, and job satisfaction for nurses working in middle-level hospital operating rooms. The journal of nursing research: JNR, 17(3), 199-211. http://dx.doi.org/10.1097/JNR.0b013e3181b2557b

Falvo, D. (2004). Effective patient education (3rd ed.). Boston: Jones and Bartlett Publishers.

Froutan, R., Khankeh, H. R., Fallahi, M., Ahmadi, F., \& Norouzi, K. (2014). Pre-hospital burn mission as a unique experience: a qualitative study. Burns: Journal of the International Society for Burn Injuries, 40(8), 1805-1812. http://dx.doi.org/10.1016/j.burns.2014.04.010

Fuller, T., \& Herold, M. (2002). Community-based Responses to Rural Transportation Issues in Ontario: a review of the Ontario Community Transportation Action Program (CTAP) 1998-2000. 2002: Online.

Ghanbari, V., Khankeh, H., Hossaini, M., Maddah, S., Karimloo, M., \& Ardalan, A. (2011). The effect of a disaster nursing education program on nurses' preparedness for responding to probable natural disasters. Iran Journal of Nursing, 24(73), 72-80.

Graneheim, U. H., \& Lundman, B. (2004). Qualitative content analysis in nursing research: concepts, procedures and measures to achieve trustworthiness. Nurse education today, 24(2), 105-112.

Haidary, S., \& Arabshahi, M. (2006). The effect of training of simulated critical in promoting awareness and making preparedness of nursing students for deal with disasters. Paper presented at the 2th International Congress on Health and Crisis Management in Disasters, Tehran.

Health Ministry of Iran. (2007). Law of universal coverage of pre-hospital emergency medicine services [database on the Internet]. from http:/www.spac.ir/hoghoghi/index-2-3.htm

Imaniyeh, M., \& Rahmdar, S. (2004). Medical technology standards. Shiraz: Tafrai publication.

Jaslow, D., Ufberg, J., \& Marsh, R. (2003). Primary injury prevention in an urban EMS system. The Journal of Emergency Medicine, 25(2), 167-170. http://dx.doi.org/10.1016/S0736-4679(03)00165-3

Joshipura, M. K., Shah, H. S., Patel, P. R., Divatia, P. A., \& Desai, P. M. (2003). Trauma care systems in India. Injury, 34(9), 686-692. http://dx.doi.org/10.1016/S0020-1383(03)00163-3

Khankeh, H. (2007). Designing a Comprehensive Model for Health Disaster Management. (Ph.D Dissertation.), Iran Medical Science University.

Lungu, K., Kamfose, V., Chilwa, B., \& Hussein, J. (2000). Are bicycle ambulances and community transport plans effective in strengthening obstetric referral systems in Southern Mulawi? International Journal of Gynecology \& Obstetrics, 70, B86. http://dx.doi.org/10.1016/S0020-7292(00)85200-5 
Mock, C., Peck, M., Juillard, C., Meddings, D., Gielen, A., \& McKenzie, L. (2011). Burn Prevention: Success Stories and Lessons Learned. World Health Organization. Retrieved from whqlibdoc.who.int/.../2011/9789241501187

Olaitan, P., \& Olaitan, J. (2005). Burns and scalds--epidemiology and prevention in a developing country. Nigerian journal of medicine: Journal of the National Association of Resident Doctors of Nigeria, 14(1), 9-16. Retrieved from http://europepmc.org/abstract/med/15832636

Polit, D. F., \& Beck, C. T. (2004). Nursing Research: Principles and Methods. Lippincott Williams \& Wilkins. Retrieved from http://www.worldcat.org/title/nursing-research-principles-and-methods/oclc/51304384

Raies Akbari, G., Yavari, M., \& Hadi, M. (2005). The duties of health and medical teams in disasters. Paper presented at the 3rd International Congress on Health, Medication and Crisis Management in Disaster, Tehran. Retrieved from http://www.civilica.com/Paper-ICHMCM03-ICHMCM03_269.html

Siddiqui, A. A., Zafar, H., \& Bashir, S. H. (2004). An audit of head trauma care and mortality. Journal of the $\begin{array}{lllll}\text { College of Physicians and Surgeons--Pakistan: JCPSP, } & \text { 14(3), }\end{array}$ http://dx.doi.org/03.2004/JCPSP.173175

Skinner, R. (2008). Improving ambulance estimated time of arrival (ETA) at hospital emergency department. Health GIS guy, 6, 78-79.

Speziale, H. S., Streubert, H. J., \& Carpenter, D. R. (2011). Qualitative Research in Nursing: Advancing the Humanistic Imperative: Lippincott Williams \& Wilkins.

Statistical Centre of Iran. (2014). Iran Statistical Year Book: Statistical Center of Iran. Retrieved from http://amar.org.ir/english/Iran-Statistical-Yearbook

Strauss, A., \& Corbin, J. (1998). Basics of qualitative research: techniques and procedures for developing grounded theory (2nd ed.). Thousand Oaks, USA: Sage Publications

Suserud, B.-O. (2002). Ambulance responses at a disaster site. Emergency nurse: The journal of the RCN $\begin{array}{llll}\text { Accident and Emergency Nursing } & \text { 22-27. }\end{array}$ $\mathrm{http}: / / \mathrm{dx}$. doi.org/10.7748/en2002.03.9.10.22.c1397

Vahedparast, H. (2005). Hospital preparedness in disasters. (Masters Thesis).

van der Velden, M. W. A., Ringburg, A. N., Bergs, E. A., Steyerberg, E. W., Patka, P., \& Schipper, I. B. (2008). Prehospital interventions: time wasted or time saved? An observational cohort study of management in initial trauma care. Emergency medicine journal: EMJ, 25(7), 444-449. http://dx.doi.org/10.1136/emj.2007.052662

World Health Organization. (2007a). Mass casualty management systems: Strategies and guidelines for building health sector capacity. Retrieved from http://www.who.int/hac/techguidance/MCM_guidelines_inside_final.pdf

World Health Organization. (2007b). Risk reduction and emergency preparedness: WHO six-year strategy for the health sector and community capacity development. Retrieved from http://www.who.int/hac/techguidance/preparedness/emergency_preparedness_eng.pdf

\section{Copyrights}

Copyright for this article is retained by the author(s), with first publication rights granted to the journal.

This is an open-access article distributed under the terms and conditions of the Creative Commons Attribution license (http://creativecommons.org/licenses/by/3.0/). 